\title{
PENINGKATAN KEMAMPUAN MANAJEMEN PEMASARAN PRODUK UNGGULAN BERBAHAN DASAR NANEAS KECAMATAN MEKARSARI BARITO KUALA PROVINSI KALIMANTAN SELATAN
}

\author{
Syafril, Yuliani, Muhammad Fahmi, Netti Rosiana Fadhilah dan Jamaluddin \\ ASMI Citra Nusantara Banjarmasin \\ E-mail : syafril.riau@gmail.com
}

\begin{abstract}
Community Service Activities by providing Training in Improvement of Marketing Management Capabilities of Leading Products Based on Pineapple in Mekarsari District are expected to increase the knowledge of SMEs, managers of BUMDES and village apparatus in marketing the products produced. One marketing technique that can be used is the marketing mix which is a combination of a number of marketing tools used by the company to convince the object of marketing or the intended target market. SMEs and BUMDES can increase sales by paying attention to products, prices, places and promotions. The combination of $4 \mathrm{P}$ in a product marketed will be able to increase the sales volume of SMEs in Mekarsari Barito Kuala District.
\end{abstract}

Keywords : Marketing Mix, SMEs, BUMDES, Mekarsari, Training

\section{PENDAHULUAN}

Pulau Kalimantan meiliki

berbagai macam tumbuhan yang

bernilai ekonomis tinggi jika dikelola

dengan baik dan profesional. Salah satunya adalah tumbuhan buah nanas yang merupakan salah buah yang tumbuh subur di Kecamatan Mekarsari.

Nanas merupakan salah satu buah yang memiliki prospek bagus untuk dikembangkan karena mudah untuk dibudidayakan, digemari masyarakat dan dapat diolah menjadi macam variasi olahan. Berdasarkan data dari BPS, Barito Kuala (Batola) adalah salah satu kabupaten dengan produksi nanas paling banyak di Kalimantan Selatan dengan produksi sebanyak 152.771 kwintal/tahun (Setyarini, 2019).

Tanaman nanas dalam pembudidayaannya memang membutuhkan tanah yang gembur dan kaya akan bahan organik, seperti yang terkandung dalam tanah gambut. Disamping itu, tanaman Nanas juga membutuhkan curah hujan yang merata sepanjang tahun dengan suhu optimum $32^{\circ} \mathrm{C}$, sesuai dengan kondisi geografis di wilayah Kalimantan, khususnya Kecamatan Mekarsari Kalimantan Selatan. Tanaman nanas dapat tumbuh baik pada iklim agak kering - basah, dataran rendah, kondisi tanah gembur dan drainase baik. Sebagian wilayah 
Kalimantan memenuhi beberapa persyaratan tersebut sehingga cukup potensial untuk dikembangkan.

Nanas merupakan salah satu jenis buah-buahan tropis yang banyak dikonsumsi masyarakat baik karena harganya murah, mudah didapat, kandungan gizi cukup tinggi, dan mudah dibudidayakan. Buah nenas memiliki kadar air yang tinggi hingga mencapai kurang lebih 80-90 \% sehingga mudah sekali mengalami perubahan fisik, kimia maupun fisiologis. Dengan demikian apabila tidak segera dipasarkan atau dilakukan penanganan lebih lanjut maka mutunya akan cepat menurun. Dengan mengolah buah nanas menjadi beraneka ragam hasil olahan maka daya simpan bisa lebih lama, mengurangi resiko busuk, dan dapat memperluas jangkauan pemasaran (Ekawati, 2019).

Kecamtan Mekarsari memiliki potensi lahan nanas seluas 360 ha dimana 110 ha sudah digunakan untuk budidaya tanaman nanas dengan jumlah produksi 2 ton/bulan (Aziz, 2019). Nanas juga merupakan salah satu produk unggulan Kabupaten Barito Kuala dan merupakan icon dari Kecamatan Mekarsari. Barito Kaula sendiri punya 2 (dua) jenis buah nanas yang menjadi unggulan, yaitu Nanas Paun dan Nanas Tamban. Kedua jenis nanas khas Batola ini punya perbedaan yang mencolok, yaitu buah Nanas Paun ukurannya cukup besar dengan daging agak pucat tapi rasanya manis asam, sedangkan Nanas Tamban ukurannya sama dengan nanas umumnya dengan daging berwarna kuning orange dengan kadar air yang banyak. Nanas yang sudah menjadi produk unggulan utamanya Nanas Tamban ini bisa menjadi berbagai produk olahan seperti sirup, dodol dan bahkan dibikin jus, dan juga bisa dikonsumsi langsung atau menjadi pelengkap jajanan pencok (rujak).

Permasalahan utama dalam pengembangan usaha kecil mikro (UKM) dan Badan Usaha Milik Desa (BUMDES) adalah berkaitan dengan pemodalan, manajemen usaha, pengelolaan keuangan dan pemasaran produk yang dihasilkan. Sebagian besar UKM dan BUMDES terutama skala usaha mikro pada industri rumahan (home industry) masih mengalami masalah dalam memperoleh dan meningkatkan penjualan secara kontinyu karena pemasaran produk yang mengandalkan cara-cara pemasaran konvensional, seperti 
penjualan melalui pameran, konsinyasi maupun penjualan secara langsung. Dengan manajemen usaha yang dilakukan ini berdampak pada biaya operasional penjualan yang cukup tinggi, perputaran modal menjadi lambat dan terhambatnya proses produksi serta volume penjualan relatif stagnan sehingga menyebabkan peluang dan potensi memperoleh pendapatan dan meraih pangsa pasar menjadi berkurang.

\section{KALAYAK SASARAN}

Kegiatan Pengabdian Kepada Masyarakat ini diberikan kepada Para pelaku UKM yang memiliki berbagai produk hasil usaha yang sebagian besar pelakunya adalah kaum perempuan menghasilkan produk dari bahan dasar nanas sepeerti kerpik nanas, dodol nanas, sirup nanas, selai nanas dan produk lain seperti keripik singkong. Selain para pelaku UKM pelatihan ini juga diikuti oleh para pengelola BUMDES dan aparat perangkat desa yang ada di Kecamatan Mekarsari. Pelatihan ini bertujuan memberikan pengetahuan dibidang pemasaran produk-produk unggulan daerah kepada para pelaku UKM dan pengelola BUMDES agar produk yang dihasilkan dapat dipasarkan baik seara offline maupun seara online.

Permsalahan utama yang dihadapi oleh para pelaku UKM dan Pengelola BUMDES dalam memasarkan produknya dapat diuraikan dengan teknik bauran pemasaran (marketing mix) yang umumnya dikenal dengan teori 4P yakni Product, Price, Place dan Prmotion. Dalam teknik pemasaran mengunakan marketing mix maka beberapa kendala dalam pemasaran dapat dipecahkan secara sederhana olej para pelaku UKM dan pengelola BUMDES Kecamatan Mekarsari.

Dari paparan permasalahan diatas mendorong Pusat Inkubasi Bisnis Usaha Kecil (PINBUK) Barito Kuala berkerja sama dengan Tim Pelaksana Inovasi Desa (TPID) memberikan pelatihan kepada seluruh Pengelola BUMDES, Pelaku UKM dan Aparatur Perangkat Desa di 13 (tiga belas) Kecamatan di Kabupaten Barito Kuala. Pelatihan di Kecamatan Mekarsari mengambil tema tentang bagaimana meningkatkan pemasaran produk-produk unggulan berbahan dasar nanas yang dihasilkan masyarakat di wilayah Kecamatan Mekarsari dan sekitarnya. Pelatihan ini dimentori oleh PINBUK Barito Kuala 
yang terdiri dari praktisi dibidang keuangan, ekonomi mikro dengan latar belakang pengalaman di bidang perbankan syariah, pemimpin Baitul Mal Wattamwil (BMT), dan juga akademisi dibidang studi ekonomi, akuntansi, serta manajemen pemasaran yang juga merupakan pelaku/pengusaha mikro.

\section{METODE PELAKSANAAN}

Pengabdian kepada masyarakat ini dilaksanakan di Aula Kecamatan Mekarsari Barito Kuala pada hari Kamis tanggal 5 Desember 2019 dari pukul 09.00 - 17.00 Wita yang dihadiri aparatur Kecamatan, pelaku UMKM, Pengelola BUMDES dan perangkat desa Kecamatan Mekarsari.

Metode pelaksanaan pada kegiatan ini dilakukan dengan metode antara lain:

a. Presentasi (penyampaian teori dan materi secara langsung)

b. Diskusi

c. Tanya Jawab

Pada saat presentasi dilakukan peserta dapat melontarkan pertanyaan secara langsung agar terjadi dialok interaktif antara pemateri dengan peserta Pelatihan Manajemen

Pemasaran Produk Unggulan

Kecamatan Marabahan Barito Kuala Kalimantan Selatan.

\section{HASIL DAN PEMBAHASAN}

Salah satu kendala bagi pelaku UKM dan pengelola Bumdes adalah bagaimana memasarkan produk-produk yang dihasilkan oleh masyarakat pelaku UKM dan binaan Bumdes di desa mereka masing-masing. Banyak keluhan yang disampaikan kepada aparatur pemerintah kecamatan Mekarsari bagaimana caranya menjual produk yang dihasilkan masyarakat seperti produk keripik nanas, dodol nanas, sirup nanas, selai nanas dan produk pertanian lainnya seperti jeruk, nenas, singkong dan durian yang selalu harganya jatuh pada saat panen tiba. Harga yang ditawakan tengkulak atau pengumpul untuk produk hasil pertanian di desa terkadang tidak mampu menutupi biaya yang telah dikeluarkan petani atau untungnya sangat tipis sehingga petani sangat dirugikan.

Para pelaku UKM di kecamatan Mekarsari secara umum memiliki keterampilan dalam pembuatan beberpa jenis makanan dan minuman karena sudah pernah mendapatkan pelatihan pengolahan produk dari berbagai macam bahan baku seperti nanas, 
singkong dan sebagainya. Dengan adanya BUMDES di desa diharapkan terjadi kerjasama dengan pelaku UKM binaan dalam memasarkan produk yang dihasilkan agar penjualan dan pendapatan pengusaha mikro di desa meningkat. Peran BUMDES sebagai motor pengerak ekonomi di desa benarbenar diharapkan berjalan dengan baik sesuai program pemerintah. Kendala yang dihadapi pelaku UKM dan BUMDES di desa dalam ham pemasaran produk memang bukan perkara yang mudah, banyak hal yang dihadapi seperti permasalahan lokasi yang jauh dari pusat kota.

\section{Marketing Mix}

Dalam ilmu pemasaran secara luas sudah dikenal dengan teknik pemasaran Markeing Mix , yaitu menurut Kotler, "Marketing mix is the set of marketing tools that the firm uses to pursue its marketing objectives in the target market" (Bauran pemasaran adalah sejumlah alat-alat pemasaran yang digunakan perusahaan untuk menyakinkan obyek pemasaran atau target pasar yang dituju). Pengertian bauran (mix) adalah terpadu atau campuran yang terdiri dari bermacammacam unsur (the mixture of elements) dimana masing-masing saling menunjang dan saling mempengaruhi untuk mencapai tujuan.

Dengan menerapkan Marketing Mix maka secara perlahan permasalahan pemasaran produkproduk yang dihasilkan pelaku usaha kecil di desa dapat diurai secara benar. Marketing mix secara umum dikenal dengan teori $4 \mathrm{P}$ yang merupakan perpaduan dari Product, Price, Place, dan Promotion. Dalam memasarkan produk yang dihasilkan seorang pemasar harus memahami beberapa hal yang melekat pada 4P tersebut seperti:

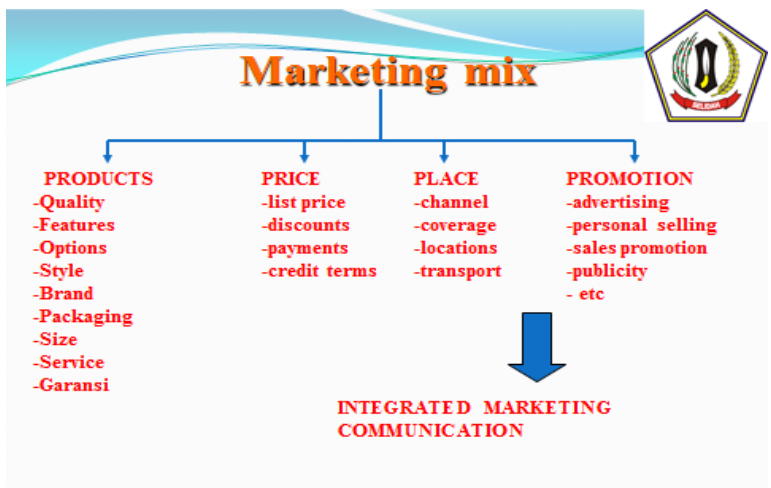

Gambar 1. Marketing Mix Tools

\section{Product}

Produk adalah serangkaian keuntungan-keuntungan yang disampaikan kepada customer. Produk adalah serangkaian keuntungankeuntungan yang disampaikan kepada customer. 
Ada beberapa pertnyaan yang harus dicari jawabannya oleh pemasar berkaitan dengan produk yang hendak dipasarkan, diantara sebagai berikut:

a. Bagaimana kualitas produknya?

b. Apa ciri khasnya? pembeda dengan pesaing, dll

c. Apakah ada produk lain/alternatif sejenis di pasaran?

d. Apakah jenis/ragam produknya?? Buah-buahan

e. Apa mereknya?

f. Bagaimanan pengemasannya?

g. Berapa besar/banyak isinya?

h. Bagaiman pelayanan ke konsumen?

i. Apa jaminan yang diberikan ke konsumen?

Jawaban atas pertanyaan diatas tentu sangat tergantung dari masingmasing pihak yang menjalaninya. Setiap pemasar dan produk memiliki jawabannya masing-masing.

\section{Price}

Price is the amount of money charged for a product or service (Kottler,2009). Jadi harga merupakan sejumlah uang yang ditukarkan untuk mendapatkan sebuah produk atau layanan oleh konsumen. Dalam menentukan harga jual harus diperhatikan beberapa hal supaya produk dapat bersaing dipasaran.
Pricing Strategy (strategi harga) Importance of: knowing the market (memahami pasar), elasticity (elastisitas), keeping an eye on rivals (menaruh perhatian terhadap kompetitor), (Abdullah, 2012).

Ada beberapa hal yang harus diperhatikan oleh penjual berkaitan dengan harga produk yang hendak dipasarkan, diantara sebagai berikut:

a. List Price $=$ daftar harga (patokan harga)

b. Discount = potongan harga (borngan, jumlah tertentu)

c Payment $=$ metode pembayaran (kas atau kredit, langsung atau transfer, dll)

d. Credit Term - syarat2 kredit (pembayaran tunda)

Place

Place The means by which products and services get from producer to consumer and where they can be accessed by the consumer (Tempat merupakan sarana di mana produk dan jasa dari produsen sampai ke konsumen, atau di mana produk dan jasa tersebut dapat diakses oleh konsumen). The more places to buy the product and the easier it is made to buy it, the better for the business and the consumer. (semakin banyak tempat 
yang mudah untuk mendapatkan atau membeli produk/jasa, semakin baik bagi bisnis dan konsumen).

Dalam hal ini pelaku UKM dan BUMDES harus memikirkan tempat mereka berjualan karena secara konvensional tempat sangat berpengaruh terhadap penjualan suatu produk. Kendala utama pemasaran produk UKM dan BUMDES Kecamatan Mekarsari dimana lokasi desa sangat jauh dari keramaian atau calon pembeli potensial. Salah satu alternatif pemecahan masalah tempat (Place) ini dapat dilakukan dengan cara pemasaran secara online melalui media internet seperti web, marketplace, instagram, whatshap group yang tidak mengenal batas wilayah. Permasalahan ini sudah dipikirkan oleh pemerintah dimana di desa sudah diberikan fasilitas internet dalam Program One Village One Internet Connection kerja sama 2 (dua) yakni Kementrian Desa dan Pembangungan Wilayah Tertinggal dan Transmigrasi dengan Kementrian Komunikasi dan Informatika yang ditempatkan servernya di setiap Kantor Kecamatan di desa-desa wilayah Kabupaten Barito Kuala.
Berikut adalah beberapa pertanyaan yang harus di jawab dalam mengembangkan strategi distribusi produk:

a. Di mana klien Anda mencari layanan atau produk Anda?

b. Toko apa yang bisa dikunjungi oleh calon klien? Apakah mereka berbelanja di mal, di toko batu bata dan semen biasa, di supermarket, atau online?

c. Bagaimana Anda mengakses saluran distribusi yang berbeda?

d. Bagaimana strategi distribusi Anda berbeda dari pesaing Anda?

e. Apakah Anda membutuhkan tenaga penjualan yang kuat?

f. Apakah Anda perlu menghadiri pameran dagang?

g. Apakah Anda perlu menjual di toko online?

\section{Promotion}

Promotion is Strategies to make the consumer aware of the existence of a product or service (strategi untuk membuat konsumen sadar akan keberadaan produk atau jasa). Promosi adalah komponen pemasaran yang sangat penting karena dapat meningkatkan pengenalan merek dan penjualan. Beberapa metode pemasaran yang dapat dilakukan oleh pelaku UKM 
dan pengelola BUMDES agar produk yang dihasilkan mendapatkan pembeli yang potensial seperti dengan iklan dan pemasaran tradisional dari mulut kemulut.

Iklan biasanya mencakup metode komunikasi berbayar seperti iklan televisi, iklan radio, media cetak, dan iklan internet. Di zaman sekarang, tampaknya ada pergeseran dalam fokus offline ke dunia online.

Word of mouth juga merupakan jenis promosi produk. Promosi dari mulut ke mulut adalah komunikasi informal tentang manfaat produk oleh pelanggan yang puas. bagian penjualan memainkan peran yang sangat penting dalam pemasaran dari mulut ke mulut. Pemasaran dengan metode Word of mouth juga bisa beredar di internet dalam bentuk viralisasi dan hal ini memiliki potensi untuk menjadi salah satu aset paling berharga yang pelaku usaha miliki dalam meningkatkan laba. Pelaku usaha melalui interaksi melalui media online yang sangat populer saat ini. Jika pelaku usaha memliki berbagai saluran media online yang sedang banyak diminati maka akan semakin terbuka pemasaran produk yang dimiliki.
Dalam menciptakan strategi promosi produk yang efektif, Anda perlu menjawab pertanyaan-pertanyaan berikut:

a. Bagaimana penjual bisa mengirim pesan pemasaran ke pembeli potensial?

b. Kapan waktu terbaik untuk mempromosikan produk?

c. Apakah penjual akan menjangkau pemirsa dan pembeli potensial melalui iklan televisi?

d. Apakah sebaiknya menggunakan media sosial dalam mempromosikan produk?

e. Apa strategi promosi pesaing?

\section{Marketing Budget}

Untuk memasarkan suatu produk tentu membutuhkan dana pemasaran (marketing budget) yang harus disiapkan oleh pelaku UKM dan pengelola BUMDES yang besarannya tergantung dari media pemasaran yang digunakan. Semakin sering melakukan promosi tentu semakin besar pula dana yang dibutuhkan. Untuk itu pelaku UKM dan pengelola BUMDES harus dapat memilih media yang paling efisien dari segi biaya disesauikan dengan keuantungan yang akan diperoleh. Salah satu promosi yang tepat telah dilakukan Pemerintah 
Kecamatan Mekarsari Barito Kuala media massa dan dikunjungi oleh turis yakni dengan rutinnya digelar Festival asing maupun lokal.

Nanas Mekarsari yang banyak diliput

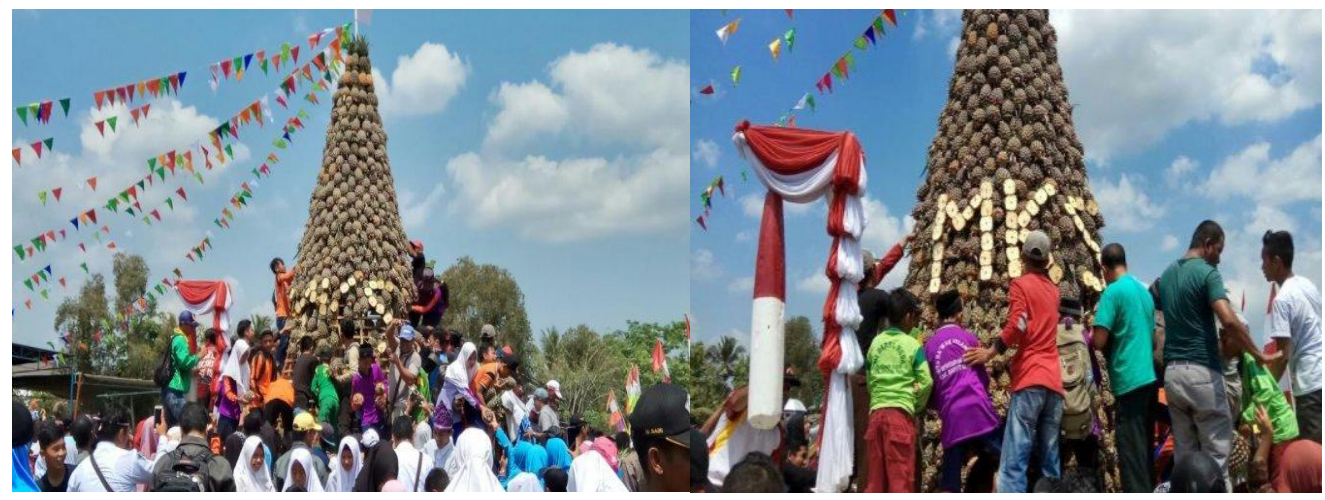

Gambar 2. Festival Nanas Mekarsari, 2019

\section{Timing}

Selain tiu diperlukan waktu yang pas (timing) dalam melakukan pemasaran yang memberikan efek yang luas terhadap pengenalan dan peningkatan penjualan produk seperti saat ada keramaian di wilayah masingmasing misalnya ulang tahun Kabupaten Barito Kuala atau Kecamatan Mekarsari, festival rakyat atau berbagai even-even yang diselenggarakan pemerintahan baik pusat maupun daerah. Hal ini tentunya berkaitan dengan biaya promosi yang murah agar produk UKM dapat bersaing dipasaran. Efisiensi biaya sangat penting berkaitan dengan penetapan harga jual produk yang ditawarkan kepada calon pembeli potensial.

\section{Dampak Kegiatan}

Dari berbagai uraian tentang teknik bauran pemasaran (marketing mix) yang diberikan pada saat pelatihan peningkatan manajemen pemasaran produk unggulan diharapkan para pelaku UKM dan pengelola BUMDES serta aparatur perangkat desa memiliki pengetahuan tentang berbagai strategi pemasaran agar produk yang dihasilkan mendapatkan pembeli potensial yang secara langsung akan meningkatkan pendapatan (laba) usaha pelaku UKM dan BUMDES. Setelah diberikan pelatihan para pelaku UKM dan BUMDES mulai melakukan evaluasi terhadap proses pemasaran yang mereka lakukan sebelumnya yang dilakukan secara konvensional.

Pengertian dampak menurut Kamus Besar Bahasa Indonesia adalah 
benturan, pengaruh yang mendatangkan akibat baik positif maupun negatif. Pengaruh adalah daya yang ada dan timbul dari sesuatu (orang, benda) yang ikut membentuk watak, kepercayaan atau perbuatan seseorang. Pengaruh adalah suatu keadaan dimana ada hubungan timbal balik atau hubungan sebab akibat antara apa yang mempengaruhi dengan apa yang dipengaruhi. (KBBI Online, 2010).

Menurut Soekidjo Notoatmodjojo (1991) dalam Ekawati (2019) bahwa keberhasilan pelaksanaan suatu program pelatihan dapat dikatakan sukses apabila dalam diri peserta pelatihan tersebut terjadi suatu proses transformasi dalam; (1) Peningkatan kemampuan dalam melaksanakan tugas, (2) Perubahan perilaku yang tercermin pada sikap, disiplin, dan etos kerja. Sedangkan Kaswan (2011) mengemukakan bahwa pelatihan merupakan suatu proses untuk meningkatkan pengetahuan dan keterampilan.

Photo2 Kegiatan Pelatihan Peningkatan Kemampuan Manajemen Pemasaran Produk Unggulan Berbahan Nanas Kecamatan Mekarsari Barito Kuala Kalimantan Selatan

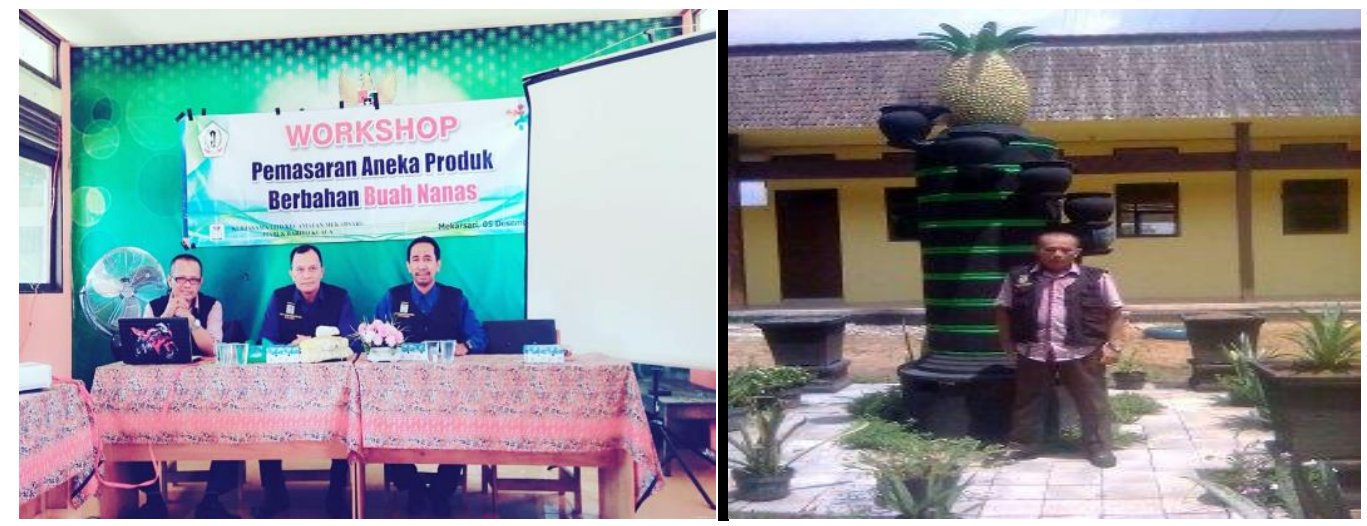

Gambar 3. Tim Pemateri Pelatihan

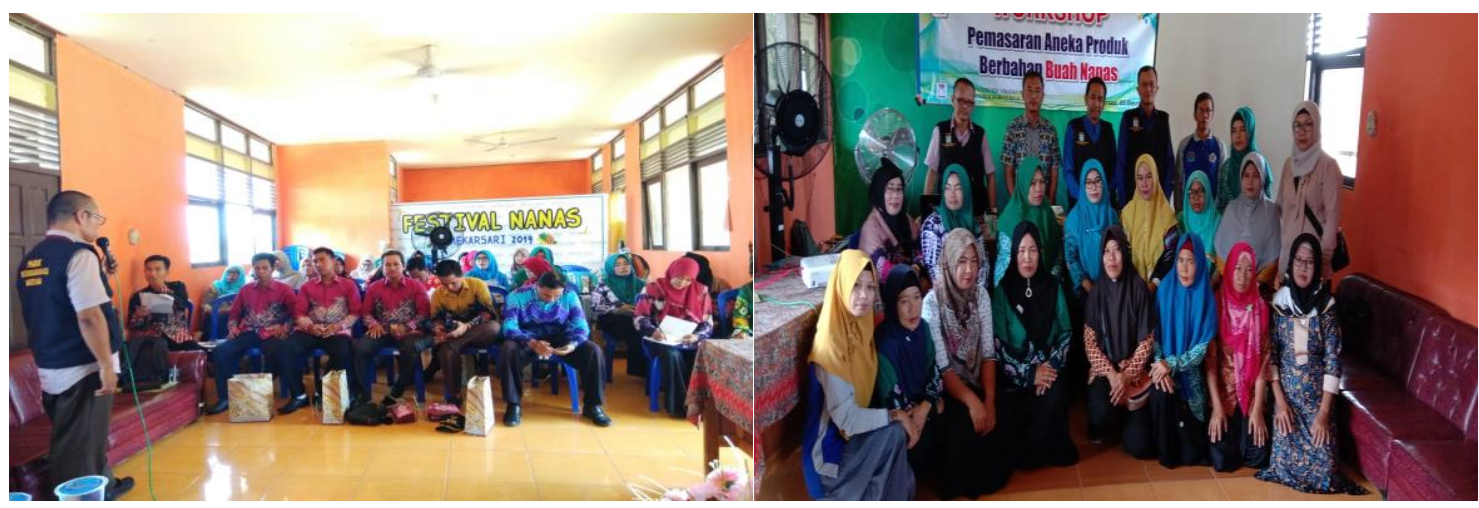


Gambar 4. Peserta Pelatihan Pelaku UKM, Pengelola BUMDES, dan Aparatur Kecamatan

\section{KESIMPULAN}

Dari hasil kegiatan Pengabdian Kepada Masyarakat ini dapat ditarik suatu kesimpulan bahwa kegiatan ini memberikan dampak yang signifikan terhadap pengetahuan pelaku UKM pengelola BUMDES dan aparatur pemerintahan desa dalam memasarkan produk yang dihasilkan dengan berbagai teknik marketing mix dimana sebelum pelatihan dilaksanakan belum memahami teknik pemasaran tersebut. Pelatihan ini juga memberikan dampat pengetahuan tentang pemasaran produk secara online dengan memanfaatkan fasilitas internet desa yang dibangun pemerintah. Pada awalnya masih banyak pelaku UKM yang belum faham memasarkan produknya secara online melauimedia internet di marketplace seperti bukalapak, tokopedia dan shoee.

\section{DAFTAR PUSTAKA}

Abdullah, Thamrin dan Francis Tantri, "Manajemen Pemasaran", 2012, Edisi 1, Cetakan 3, Rajawali Pers, Jakarta

Aziz, Moch, 2019, https://banjarmasin.tribunnews.c om/2019/09/11/produksi-capai2-ton-per-bulan-ini-keunggulannanas-mekarsari

Ekawati, Sondang Sylvia Manurung, Ellyta, dan Donna Youlla, 2019, "Diversifikasi Penggoahan Buah Nanas Desa Galang Dalam Meningkatkan Pendapatan Petani Nanas," Jurnal Al Ikhlas, Vol. 5, No.1, Oktober 2019

Kaswan, 2011, "Pelatihan dan Pengembangan”, Cetakan 1, Alfabeta, Bandung

Kottler, Philip dan Kevin L Keller, 2009, "Manajemen Pemasaran” Edisi 12 Jilid 1, PT Indeks, Jakarta

Setyarini, Ariska Desi, 2019, "Tata Niaga Buah Nanas Tamban di Desa Mekarsari Kecamatan Mekarsari Kabupaten Barito Kuala” ULM, Banjarmasin 